Quim. Nova, Vol. 25, No. 2, 214-220, 2002.

\title{
EXTRAÇÃO POR FLUIDO SUPERCRÍTICO DE ALGUNS INSETICIDAS CARBAMATOS EM AMOSTRAS DE BATATA, COM DETERMINAÇÃO POR HPLC/FLUORESCÊNCIA E CONFIRMAÇÃO POR HPLC/ ESPECTROMETRIA DE MASSAS
}

\author{
Gilvanda Silva Nunes* e Teresa Cristina R. Santos \\ Departamento de Tecnologia Química, CCET, Universidade Federal do Maranhão, Av. Portugueses, s/n, Campus Bacanga, \\ 65080-040 São Luís - MA \\ Damiá Barceló
}

Departamento Química Ambiental, Centro de Investigación y Desarrollo - CID/CSIC, C/ Jordi Girona, 18-26, 08035 Barcelona Espanha

Alexandre Santos Pimenta

Departamento de Engenharia Florestal, Universidade Federal de Viçosa, Av. P. H. Rolfs, s/n, 36570-000 Viçosa - MG

Maria Lúcia Ribeiro

Instituto de Química, Universidade Estadual Paulista, Rua Prof. Francisco Degni, s/n, 14800-901 Araraquara - SP

Recebido em 21/11/00; aceito em 8/8/01

\begin{abstract}
SUPERCRITICAL FLUID EXTRACTION FOR SOME CARBAMATE INSECTICIDES IN POTATOES SAMPLES, WITH HPLC/ FLUORESCENCE DETERMINATION AND HPLC/MASS SPECTROMETRY CONFIRMATION. Six supercritical fluid extraction (SFE) methods were tested, by varying the following operational parameters: $\mathrm{CO}_{2}$ pressure, time and temperature of extraction, type and proportion of static modifier, and Hydromatrix ${ }^{\circledast} / \mathrm{sample}$ rate into cell. Firstly, insecticide carbamates were extracted from spiked potatoes samples (fortification level of $0,5 \mathrm{mg} \cdot \mathrm{Kg}^{-1}$ ) by using SPE procedures, and then final extracts were analyzed HPLC/fluorescence. Good performance was observed with SFE methods that operated with values of temperature and $\mathrm{CO}_{2}$ pressure of $50{ }^{\circ} \mathrm{C}$ and 350 bar, respectively. Best efficiency was obtained when it was used acetonitrile as a modifier (3\% on the cell volume), and Hydromatrix ${ }^{\otimes} / \mathrm{sample}$ rate of $2: 1$. Static time was of $1 \mathrm{~min}$; total extraction time was of $35 \mathrm{~min}$; dynamic extraction was performed with $15 \mathrm{~mL}$ of $\mathrm{CO}_{2}$, and it was used methanol $(2 \mathrm{~mL})$ for the dissolution of the final residue. In such conditions, pesticide recoveries varied from 72 to $94 \%$, depending on the analyzed compound. In higher extraction temperatures, a rapid degradation was observed for some compounds, such as aldicarb and carbaryl; presence of their metabolites was further confirmed by HPLC-APCI/MS in positive mode. Detection limits for chromatographic analysis varied from 0,2 to $1,3 \mathrm{ng}$.
\end{abstract}

Keywords: SFE method; HPLC/FS; HPLC-APCI/MS; potatoes; pesticides; carbamate insecticides.

\section{INTRODUÇÃO}

A necessidade de se analisar resíduos de pesticidas em alimentos, para efeito de regulamentação e controle, depara-se continuamente com problemas analíticos complexos, porque uma grande variedade de substâncias estruturalmente diferentes deve ser determinada em um amplo número de produtos agrícolas ou alimentos em geral. Por outro lado, os sistemas atuais de distribuição de alimentos exigem análises rápidas. Portanto, são necessários métodos analíticos que possam oferecer resultados seguros e de forma rápida, de modo a atestar, em um tempo normalmente inferior a $24 \mathrm{~h}$, se os produtos que apresentaram contaminação devem ser retirados do mercado, ou se sua importação deve ser cancelada ${ }^{1}$.

$\mathrm{Na}$ área de análise de resíduos de pesticidas, alguns aspectos práticos devem ser levados em consideração. Para fazer cumprir a legislação vigente, os laboratórios de controle e de execução de programas de vigilância empregam, em geral, métodos multiresíduos, que cobrem uma ampla faixa de pesticidas de distintas famílias (alguns métodos cobrem até 300 pesticidas), ou como segunda opção, utilizam métodos seletivos que se aplicam a pesticidas da mesma família ou a um único princípio ativo. Portanto, nem sempre tais métodos são suficientemente sensíveis para todos os compostos utilizados $^{2}$. Os métodos convencionais, mesmo os mais seletivos, cos-

*e-mail: vandasn@terra.com.br tumam empregar um grande número de 'etapas de bancada', resultando na utilização de grandes volumes de solventes, utilizados nos procedimentos de extração e cleanup, além de um tempo de análise bastante elevado.

$\mathrm{Na}$ análise de pesticidas, técnicas de cromatografia em fluido supercrítico $(\mathrm{SFC})^{3,4}$ e extração em fluido supercrítico $(\mathrm{SFE})^{3-5}$ foram introduzidas no final da década de 80 , como uma das alternativas para o desenvolvimento de procedimentos de extração. Desta forma, nos casos em que as recuperações dos métodos SFE são satisfatórias para determinados princípios ativos, os métodos que empregam procedimentos de partição líquido-líquido ou sólido-líquido podem ser paulatinamente substituídos ${ }^{3}$. Técnicas de extração empregando vácuo ou elevadas pressão e temperatura (instrumentos Soxhlet, por exemplo $)^{6}$ têm sido utilizadas na etapa de extração dos pesticidas em matrizes aquosas ou sólidas (alimentos, solo). Entretanto, tais técnicas apresentam a desvantagem de acarretar a degradação térmica de grande parte dos pesticidas mais polares, como é o caso dos inseticidas carbamatos e organofosforados. Uma vez que o fluido supercrítico pode ser visto como sendo tanto um gás quanto um líquido, ele oferece a grande vantagem de participar como ambas as fases nas técnicas de extração ${ }^{7}$, além de exibir elevado coeficiente de difusão, que favorece o processo de extração, sobretudo em matrizes sólidas.

Alguns procedimentos têm sido propostos para SFE de pesticidas, mas de um modo geral a técnica deve ser otimizada, e não tem se mostrado muito eficiente nas análises multiresíduo ${ }^{3}$. Lopez-Avila e 
seus colaboradores ${ }^{8}$ descreveram um procedimento de extração de pesticidas em alimentos infantis, utilizando como extrator a fase ISCO SFX 2-10, e acetonitrila como modificador de matriz, seguido de análise por imunoensaios. Sete carbamatos e alguns dos seus principais produtos de degradação foram extraídos de matrizes aquosas por SFE, e seqüencialmente analisados por cromatografia gasosa (detector termiônico nitrogênio-fósforo, NPD) ${ }^{4}$. Os autores utilizaram, como agente dispersante/secante, terra diatomácea. ValverdeGarcía e colaboradores ${ }^{9}$ introduziram o sulfato de magnésio anidro como agente secante, e demonstraram a eficiência do método na extração do inseticida metamidofos (organofosforado) em amostras vegetais. Mais tarde, esse mesmo grupo ${ }^{10}$ testou o sulfato de magnésio na análise por SFE de alguns pesticidas de variadas polaridades (carbamatos, organoclorados e organofosforados), evidenciando que a técnica é mais apropriada à extração de compostos de polaridade variando entre média a alta. Hopper ${ }^{11}$ empregou a técnica SFE para efetuar uma etapa prévia de extração/purificação, na determinação de resíduos de inseticidas organoclorados e organofosforados, em amostras com elevado teor de gordura. Para tanto, utilizou terra diatomácea peletizada (Hydromatrix ${ }^{\circledR}$ ) como agente dispersante $\mathrm{e}$ acetonitrila como modificador, e obteve resultados de recuperação satisfatórios, mesmo para os compostos de menor polaridade.

No presente trabalho, foram avaliados seis diferentes procedimentos de SFE para análise de cinco inseticidas carbamatos e alguns dos seus produtos de degradação em amostras de batata, com base na eficiência de diferentes combinações amostra/Hydromatrix ${ }^{\circledR} /$ modificador, e variando ainda alguns parâmetros operacionais, como temperatura, pressão e tempo total de extração. Após extração dos compostos, a determinação final se deu por cromatografia líquida de alta eficiência (HPLC), acoplada a detector por fluorescência (FS).
A confirmação da presença de produtos de degradação foi obtida por meio de HPLC acoplada a um espectrômetro de massas (MS), com interface APCI (ionização química à pressão atmosférica).

\section{PARTE EXPERIMENTAL}

\section{Reagentes e solventes}

Todos os solventes utilizados foram de grau resíduo (Mallinkrodt, Merck), previamente filtrados em membranas de $0,45 \mu \mathrm{m}$ de diâmetro de poro. A água deionizada foi de grau Milli- $\mathrm{Q}^{\circledR}$, produzida a $18,2 \mathrm{M} \Omega \mathrm{cm}^{-1}$. Para a eluição cromatográfica, utilizou-se também água grau HPLC (Merck). As soluções-estoque (1000 ng. $\left.\mu \mathrm{L}^{-1}\right)$ dos inseticidas carbamatos e dos seus produtos de degradação foram preparadas a partir dos padrões de referência certificados (pureza $>98 \%$, Dr. Ehrenstorfer, Alemanha), com a dissolução de quantidades exatas dos princípios ativos em metanol grau HPLC. A Tabela 1 fornece algumas informações acerca das propriedades dos inseticidas selecionados para estudo. As soluções de trabalho (entre 0,001 e $20 \mathrm{ng} . \mu \mathrm{L}^{-1}$ ) foram preparadas imediatamente antes do uso, por meio de diluição da solução estoque com metanol. O dessecante Hydromatrix ${ }^{\circledR}$ foi obtido da Varian (Califórnia, EUA), e os reagentes orto-ftalaldeído (OPA), mercaptoetanol (MERC) e formiato de amônia, da Aldrich Chem. Co. (Steinheim, Alemanha). A solução fluorogênica foi preparada sempre no dia do uso, pela mistura de $50 \mathrm{mg}$ de OPA (dissolvidos em $5 \mathrm{~mL}$ de metanol) em $500 \mathrm{~mL}$ de tampão tetraborato de sódio. A mistura foi filtrada em membranas de $0,5 \mu \mathrm{m}$ de poro, degaseificada em ultrassom e, em seguida, adicionados $25 \mu \mathrm{L}$ do reagente MERC. Esta solução foi armazenada ao abrigo da luz, permanecendo estável por no máximo $24 \mathrm{~h}$.

Tabela 1. Algumas propriedades físico-químicas e toxicológicas dos inseticidas selecionados para estudo

\begin{tabular}{llccc}
\hline Composto & $\begin{array}{c}\text { Estrutura } \\
\text { Química }\end{array}$ & $\begin{array}{c}\text { Massa } \\
\text { molar } \\
\left(\mathrm{g} \cdot \mathrm{mol}^{-1}\right)\end{array}$ & $\begin{array}{c}\text { Solubilidade } \\
\left(\mathrm{g} . \mathrm{L}^{-1}, \mathrm{a} 20^{\circ} \mathrm{C}\right)\end{array}$ & $\begin{array}{c}\mathrm{LD}_{50} \\
\text { oral em ratos } \\
\left(\mathrm{mg}_{\mathrm{kg}} \mathrm{kg}^{-1}\right)\end{array}$ \\
\hline
\end{tabular}

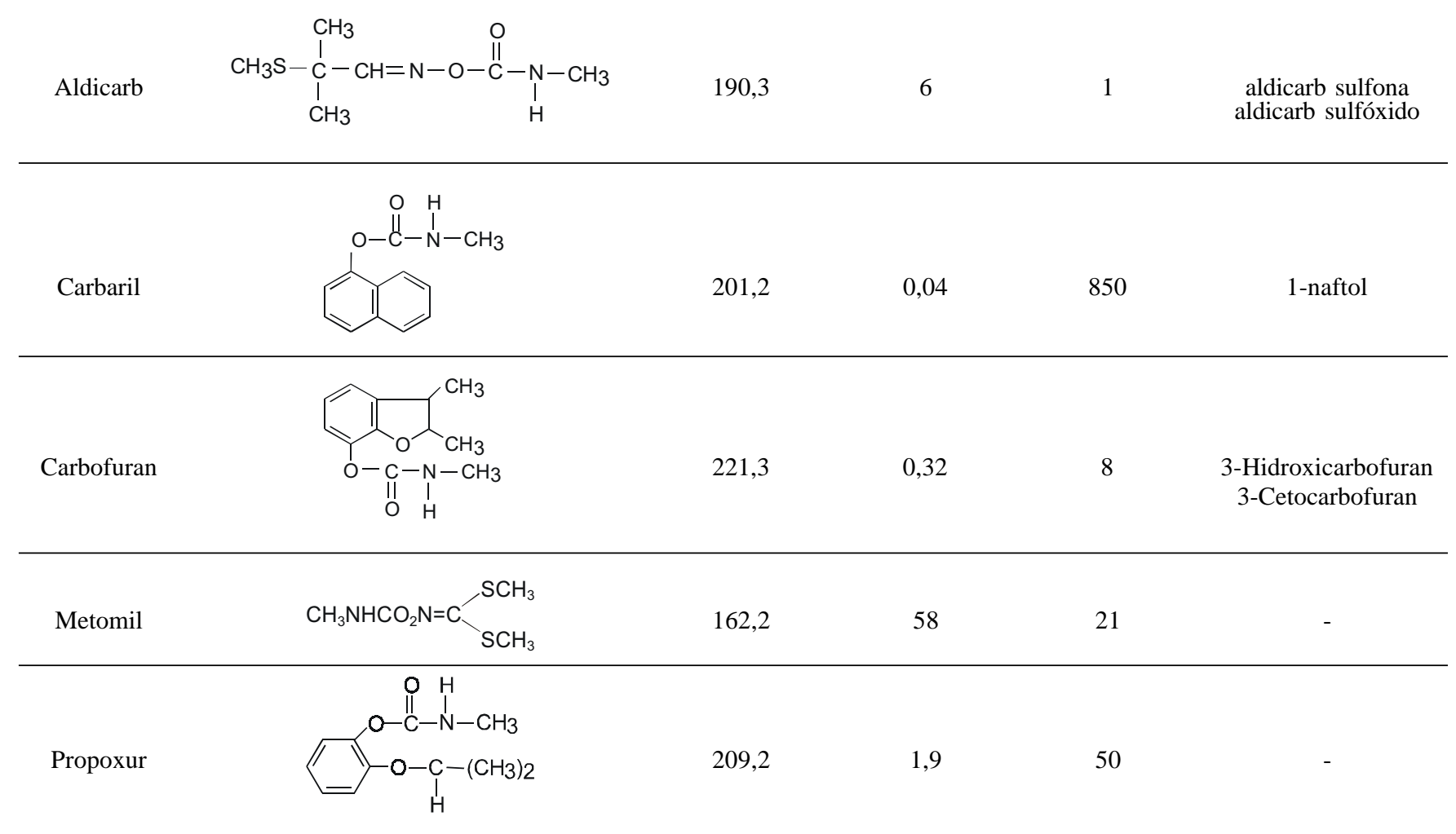




\section{Equipamentos, acessórios e procedimentos}

Para a extração em fluido supercrítico (SFE)

Foi utilizado um sistema SFE da HP, modelo 7680T, composto de um cilindro pressurizado contendo $\mathrm{CO}_{2}$; duas bombas de alta pressão (HP, modelo 260D), uma para o doseamento do gás $\mathrm{CO}_{2}$ (grau SFE/SFC, da Air Products, Madri), e a segunda para o doseamento do modificador (acetonitrila ou metanol), a uma proporção constante do modificador em relação ao volume da célula; dois reservatórios para os modificadores, além de um forno contendo a célula de extração (de aço inoxidável, Chem Tube, Harbor City, CA, EUA). A Figura 1 mostra o diagrama para a extração em fluido supercrítico.

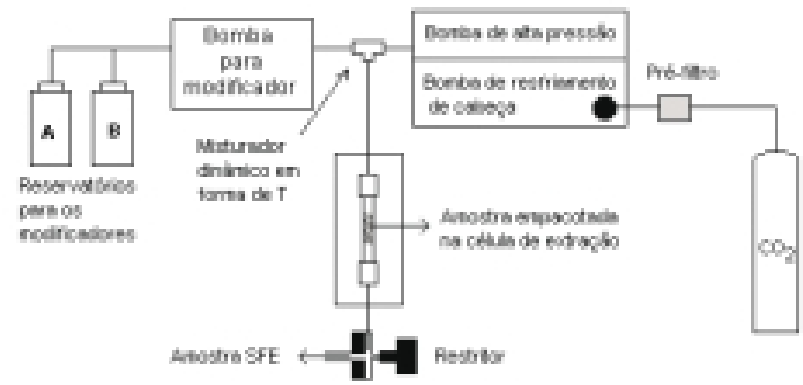

Figura 1. Diagrama esquemático do sistema de extração em fluido supercrítico usado no preparo dos extratos

Para a obtenção dos extratos, aqui denominados de 'extratos SFE', foram adotados seis diferentes métodos, cujos parâmetros operacionais são apresentados na Tabela 2. Primeiramente, as amostras de batata foram lavadas, descascadas, trituradas e depois fortificadas com os cinco inseticidas $\left(0,5 \mathrm{mg} \cdot \mathrm{Kg}^{-1}\right.$ para cada princípio ativo). As amostras fortificadas foram misturadas com Hydromatrix $^{\circledR}$ sendo, em seguida, levadas às células de extração. Hydromatrix ${ }^{\circledR}$ foi utilizado com o objetivo de retirar a água presente, além de melhor dispersar a amostra no fluido supercrítico. A extração dinâmica se deu com $15 \mathrm{~mL}$ de $\mathrm{CO}_{2}$, e a retomada do resíduo final, com $2 \mathrm{~mL}$ de metanol. Após a aplicação do fluido contendo diferentes proporções do modificador, a variados valores de pressão e temperatura, os extratos SFE foram finalmente coletados, filtrados em filtros Millex ${ }^{\circledast}$ (Millipore) e destinados às análises cromatográficas por HPLC/FS e HPLC-APCI/MS. Foram efetuadas três repetições de extração SFE para cada método testado.

\section{Para análise por HPLC/fluorescência}

O equipamento utilizado nesta parte do trabalho, esquematizado na Figura 2, consistiu de um sistema analisador de carbamatos

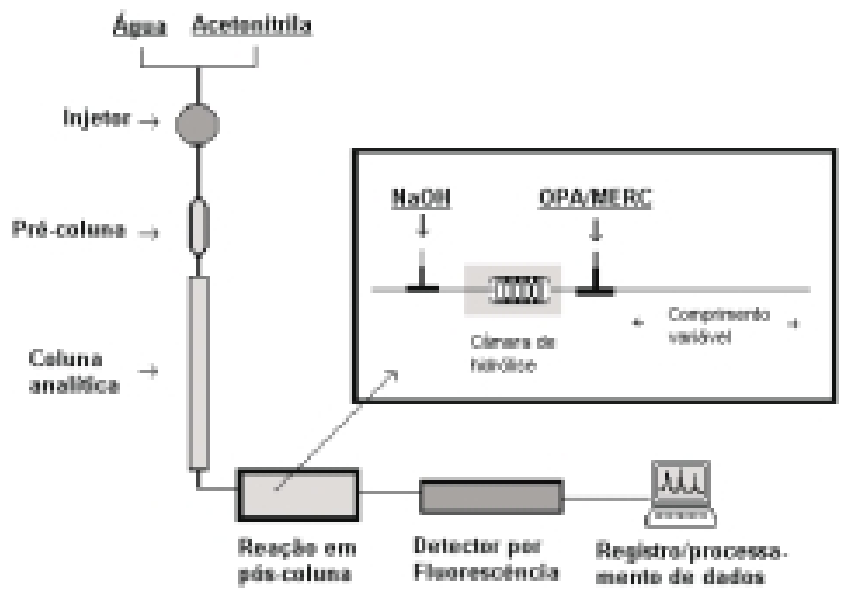

Figura 2. Diagrama esquemático do sistema HPLC/fluorescência utilizado na análise dos extratos obtidos após extração em fluido supercrítico

(Carbamate Analysis System - CAS, Waters - Divisão da Millipore, Milford, MA, EUA), formado de dois sistemas de bombeamento multisolvente (Waters, modelo 600E), um para a fase móvel e outro para os reagentes utilizados na reação fluorogênica em pós-coluna ( $\mathrm{NaOH}$ e OPA/mercaptoetanol). As bombas foram controladas pelo sistema controlador de gradiente de solvente (PCRDS), que manteve o fluxo dos reativos de $0,5 \mathrm{~mL} \cdot \mathrm{min}^{-1}$. As temperaturas dos fornos da coluna e pós-coluna foram fixadas em 30 e $80^{\circ} \mathrm{C}$, respectivamente. $\mathrm{O}$ sistema de detecção foi o detector por fluorescência da Waters (modelo 470) e os parâmetros espectroscópicos foram: $\lambda_{\text {excitaca õo }}=339 \mathrm{~nm}$, $\lambda_{\text {emissão }}=445 \mathrm{~nm}$, com largura de banda de $18 \mathrm{~nm}$. O sistema de injeção consistiu de um injetor do tipo universal U6K (Califórnia, EUA), e o volume de injeção (para extratos ou solução padrão) foi de $200 \mu \mathrm{L}$. A coluna cromatográfica utilizada foi de fase reversa, Supelcosil-C ${ }_{18}(25 \mathrm{~cm} \mathrm{x} \mathrm{4,6} \mathrm{mm} \mathrm{d.} \mathrm{i.)} \mathrm{empacotada} \mathrm{com} \mathrm{partículas} \mathrm{de}$ sílica esféricas com $5 \mu \mathrm{m}$ de diâmetro (Supelco, Inglaterra). O sistema de integração/ monitoramento/processamento consistiu de um modelo Waters 745B. Como fase móvel foi utilizada uma mistura água-metanol-acetonitrila (A-B-C), a um fluxo de 1,5 ml. $\mathrm{min}^{-1}$. O programa gradiente utilizado foi o seguinte: polaridade decrescendo de $88 \% \mathrm{~A}-12 \% \mathrm{~B}-0 \% \mathrm{C}$ para $68 \% \mathrm{~A}-16 \% \mathrm{~B}-16 \% \mathrm{C}$ durante os primeiros $4,1 \mathrm{~min}$, e então para $30 \% \mathrm{~A}-35 \% \mathrm{~B}-35 \% \mathrm{C}$ até o tempo de $16,1 \mathrm{~min}$, retornando por fim a $88 \% \mathrm{~A}-12 \% \mathrm{~B}-0 \% \mathrm{C}$ durante os últimos 2,9 min (tempo total de corrida cromatográfica: $19 \mathrm{~min}$ ). Para manter a fase móvel e os regentes de pós-coluna degaseificados, um fluxo de gás hélio foi mantido a $200 \mathrm{~mL} \cdot \mathrm{min}^{-1}$ nos respectivos recipientes. Todas as injeções foram realizadas em duplicata, e os cálculos de concentração foram baseados em curvas de calibração.

Tabela 2. Parâmetros operacionais dos procedimentos SFE adotados

\begin{tabular}{|c|c|c|c|c|c|c|}
\hline Procedimento & $\begin{array}{c}\text { Relação } \\
\text { Hydromatrix }^{\circledR} / \text { amostra }\end{array}$ & $\begin{array}{l}\text { Pressão } \\
\text { (bar) }\end{array}$ & $\begin{array}{c}\text { Temperatura } \\
\left({ }^{\circ} \mathrm{C}\right)\end{array}$ & $\begin{array}{l}\text { Modificador } \\
(\%)\end{array}$ & $\begin{array}{c}\text { Fluxo } \mathrm{CO}_{2} \\
\text { supercrítico } \\
\left(\mathrm{mL} \cdot \mathrm{min}^{-1}\right)\end{array}$ & $\begin{array}{l}\text { Tempo Total } \\
\text { (min) }\end{array}$ \\
\hline A & $2: 1$ & 350 & 50 & acetonitrila (5\%) & 2,0 & 30 \\
\hline B & $2: 1$ & 350 & 40 & acetonitrila $(10 \%)$ & 2,0 & 30 \\
\hline $\mathrm{C}$ & $2: 1$ & 350 & 50 & metanol $(2,5 \%)$ & 1,5 & 35 \\
\hline $\mathrm{D}$ & $2: 1$ & 350 & 60 & metanol $(5 \%)$ & 2,0 & 20 \\
\hline $\mathrm{E}$ & $2: 1$ & 350 & 50 & acetonitrila $(10 \%)$ & 1,5 & 35 \\
\hline $\mathrm{F}$ & $2: 1$ & 350 & 50 & acetonitrila (3\%) & 1,5 & 35 \\
\hline
\end{tabular}


Para análise por HPLC/espectrometria de massas

Um volume de $20 \mu \mathrm{L}$ do extrato foi injetado por meio do injetor universal U6K (California, EUA). Para a separação cromatográfica, foi utilizada uma coluna em fase reversa $\mathrm{C}_{18}$-Zorbax $(15 \mathrm{~cm} \mathrm{X}$ 4,6 mm d.i), empacotada com partículas de $5 \mu \mathrm{m}$, e uma mistura acetonitrila/água (a água contendo formiato de amônio a 0,05 mol. $\mathrm{L}^{-1}$ ), como fase móvel, a um fluxo de 1,0 mL. $\mathrm{min}^{-1}$. Na análise do aldicarb e seus produtos de degradação, o processo de eluição começou com $5 \%$ de acetonitrila, aumentando linearmente durante $10 \mathrm{~min}$, até $30 \%$ de acetonitrila, e então retornando a $5 \%$ nos últimos 20 min (tempo total da corrida cromatográfica: $30 \mathrm{~min}$ ), de modo a serem separadas as substâncias mais polares. Foi utilizado um sistema de bombas binárias Waters ${ }^{\mathrm{TM}}$, modelo 616, acoplado a um controlador Waters, modelo 600S (Waters, Milford, MA, EUA). Detalhes do esquema experimental por HPLC/MS foram anteriormente descritos ${ }^{12,13} \cdot \mathrm{Na}$ análise do carbaril e seu principal produto de degradação (1-naftol), uma mistura acetonitrila/água (ambos contendo $0,1 \%$ de ácido acético), a um fluxo de $1 \mathrm{ml}^{\mathrm{min}} \mathrm{m}^{-1}$, foi usada como fase móvel. O processo de eluição começou com a fase móvel contendo $5 \%$ de acetonitrila, aumentando linearmente durante $30 \mathrm{~min}$ até $100 \%$ de acetonitrila. Detalhes experimentais e otimização da separação foram descritos anteriormente ${ }^{13}$. Para a fragmentação iônica, detecção por MS e confirmação dos picos, foi empregado um espectrômetro de massas VG Platform (Micromass, Manchester, Inglaterra), equipado com a interface de ionização química a pressão atmosférica (APCI). Os parâmetros operacionais fixados foram: fluxo de gás de nebulização: $10 \mathrm{~L} / \mathrm{h}$; fluxo de gás secante $\left(\mathrm{N}_{2}\right): 300 \mathrm{~L} / \mathrm{h}$; potencial aplicado: $20 \mathrm{~V}$ para o carbaril e 1-naftol, e $30 \mathrm{~V}$ para o aldicarb e seus produtos de degradação; voltagem da coroa: $3,2 \mathrm{kV}$; modo de ionização: positivo; temperaturas da fonte de íons e da sonda APCI: 150 e $350^{\circ} \mathrm{C}$, respectivamente. $\mathrm{O}$ equipamento foi controlado pelo sistema de dados MassLynx ${ }^{\mathrm{TM}}$, e os cromatogramas foram registrados, por monitoramento dos tempos de retenção, através da condição SIR (selected ion recording), em uma faixa de $\mathrm{m} / \mathrm{z}$ entre 80 e 250 , de modo a selecionar-se cada molécula protonada ou íon fragmentado. As injeções e monitoramentos de fragmentações foram realizados em duplicata.

\section{RESULTADOS E DISCUSSÃO}

\section{Avaliação das técnicas cromatográficas}

\section{Análise quantitativa e confirmatória por HPLC-APCI/MS}

A Tabela 3 lista os valores de $m / z$ usados para confirmação dos picos dos compostos analisados por LC-APCI/MS no modo SIR. Sob as condições cromatográficas descritas na parte experimental, o carbaril foi eluído em aproximadamente $16 \min \left(t_{r} \sim 15,6 \mathrm{~min}\right)$, e seguiu os modelos gerais de fragmentação, já descritos na literatu$\mathrm{ra}^{14}$. Os íons usados para identificação foram: $[\mathrm{M}+\mathrm{H}]^{+}=202 e[\mathrm{M}+\mathrm{H}-$ $57]^{+}=145$ (onde $57=\mathrm{CH}_{3} \mathrm{NCO}$ ), equivalentes ao pico molecular protonado e ao pico originado da reação ácida de hidrólise do carbaril, com conseqüente formação do 1-naftol protonado $\left[\mathrm{C}_{10} \mathrm{H}_{8} \mathrm{O}\right]^{+}$, respectivamente. Os picos de m/z 145 e 202 correspondem, respectivamente, ao pico base e ao segundo mais abundante, em uma potência de fragmentação de 20 V. A Figura 3 mostra o cromatograma de íos totais (TIC) e o registro do íon selecionado (SIR), em relação aos íons 145, 202 e 177, usados para identificar o pesticida em um dos extratos SFE. Os picos 145 e 202 foram predominantes, mas na grande maioria dos extratos o pico 177 também esteve presente, indicando uma expressiva decomposição do carbaril, mesmo antes da análise cromatográfica. O pico 177 ( $t_{r} \sim 18,4 \mathrm{~min}$ ) corresponde, na verdade, ao aduto $[145+32]^{+}$, e está associado à molécula do 1-naftol que se uniu às moléculas intactas do metanol. Volmer et al. ${ }^{15}$ sugerem que,

Tabela 3. Íons selecionados para análise do inseticidas aldicarb e carbaril, e seus respectivos produtos de degradação por HPLC-APCI/ MS

\begin{tabular}{ll}
\hline Composto & Íons selecionados $(\mathrm{m} / \mathrm{z})$ \\
\hline Carbaril & 145,202 \\
1-naftol & 177 \\
Aldicarb & 116,191 \\
Aldicarb sulfóxido & 132,207 \\
Aldicarb sulfona & 223 \\
\hline
\end{tabular}

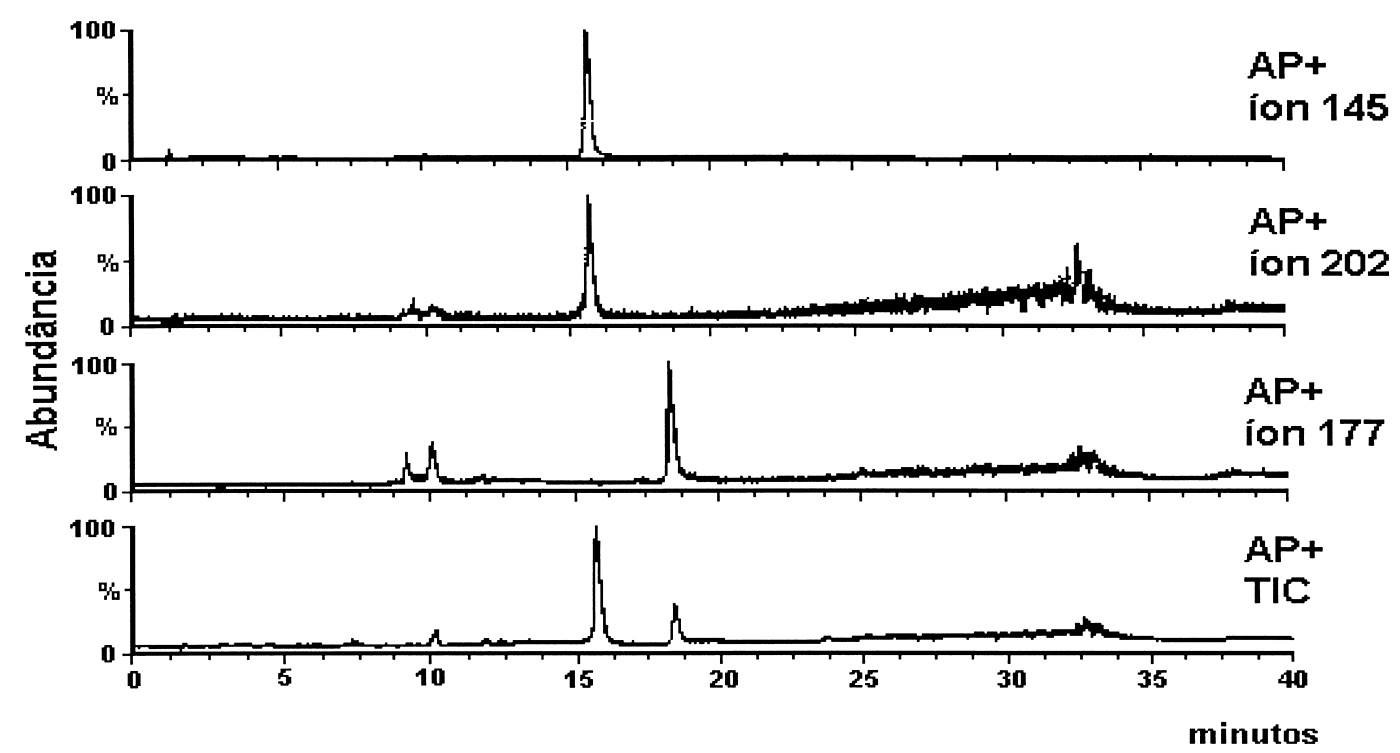

Figura 3. Cromatograma obtido por LC/APCI-MS, dos compostos carbaril e 1-naftol, presentes em um extrato de batata, fortificado a 0,5 mg.kg-1 de carbaril. Acima, os íons com m/z 145 e 202 ( para identificação do carbaril) e 177 (para identificação do 1-naftol, quando presente); abaixo, o cromatograma de ions totais (TIC), mostrando os picos do carbaril $\left(t_{r} \sim 15,6\right.$ min) e do 1-naftol $\left(t_{r} \sim 18,4 \mathrm{~min}\right)$ 
a baixas temperaturas de vaporização e da fonte, certos adutos iônicos podem ser formados da combinação de moléculas do analito e/ou um dos produtos de degradação com o solvente orgânico presente.

Um típico cromatograma iônico total (TIC) obtido por LC/MS para padrões dos compostos aldicarb, aldicarb sulfóxido e aldicarb sulfona, é mostrado na Figura 4. Através do recurso de SIR, foi possível o isolamento dos íons correspondentes a cada composto em questão, o que resultou na eliminação de interferências e na melhoria da sensibilidade do método cromatográfico. Para o aldicarb e o aldicarb sulfóxido, os íons [M-74] ${ }^{+}$foram mais abundantes; em relação ao composto aldicarb sulfona, $100 \%$ de abundância foi obtida para o íon
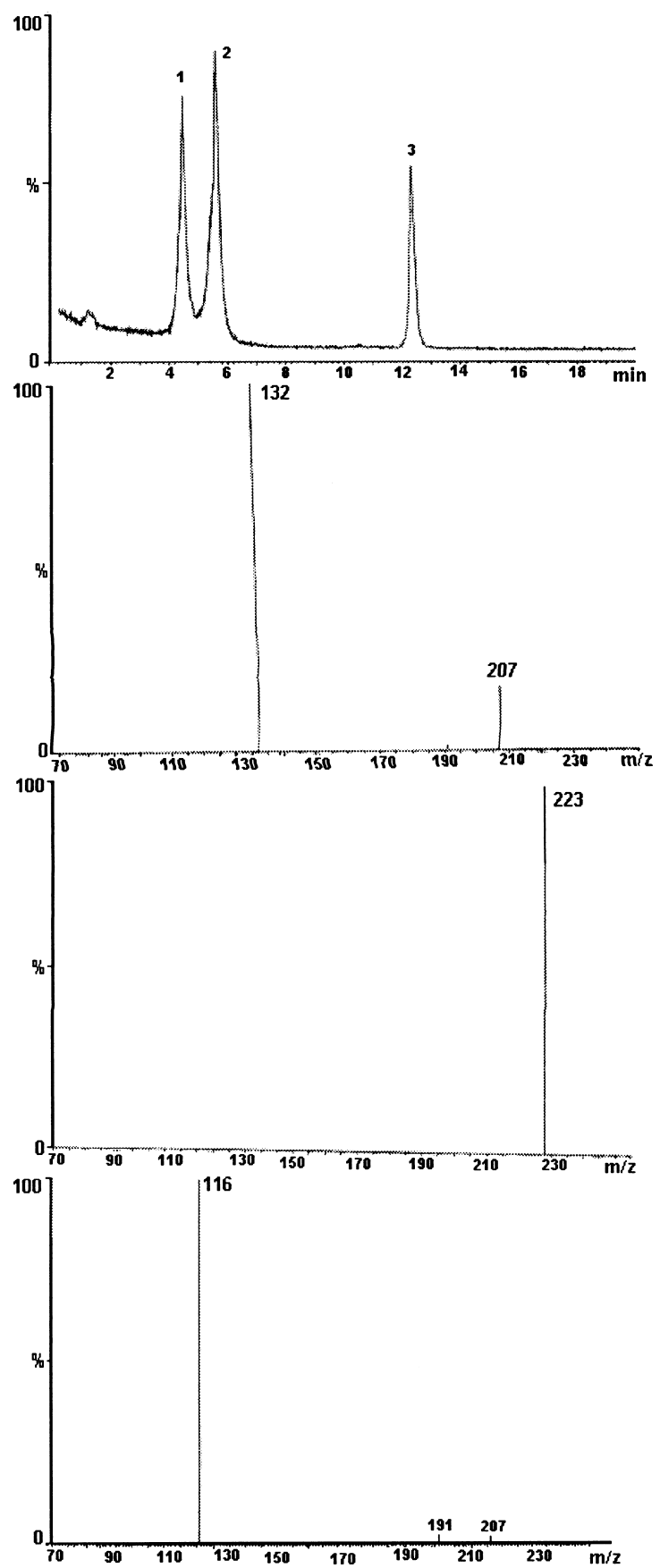

Figura 4. Cromatograma iônico total (TIC) obtido por LC-APCIMS para os compostos aldicarb sulfóxido (1), aldicarb sulfona (2) e aldicarb (3). Espectros de massa obtidos para compostos na mesma ordem molecular protonado, $[\mathrm{M}+\mathrm{H}]^{+}$. $\mathrm{O}$ estudo envolvendo padrões mostrou também que a reprodutibilidade, a linearidade e o limite de detecção (em relação ao instrumento) foram adequados para monitoramento de resíduos de aldicarb e carbaril (mais susceptíveis à degradação em elevadas temperaturas), além de seus produtos de degradação (Tabela 4). Além disso, no modo APCI positivo, melhores respostas foram observadas, confirmando outros estudos já efetuados envolvendo o uso de LC/MS para análise de carbamatos ${ }^{13,16}$.

Tabela 4. Reprodutibilidade, linearidade e limites de detecção para os inseticidas carbaril, aldicarb e seus produtos de degradação, analisados por LC-APCI/MS

\begin{tabular}{ccccc}
\hline Composto & Linearidade & \multicolumn{2}{c}{ Limite de deteccão (ng) } & CV (\%) \\
& (ng) & HPLC/MS & HPLC/FS & \\
\hline Carbaril & $0,8-125$ & 0,6 & 0,4 & 5,6 \\
1-naftol & $0,6-150$ & 0,4 & 0,2 & 7,3 \\
Aldicarb & $1-250$ & 0,5 & 0,3 & 3,5 \\
Aldicarb & $0,6-200$ & 0,5 & 0,2 & 4,2 \\
sulfóxido & & 1,3 & 0,5 & 7,0 \\
Aldicarb & $2-500$ & & & \\
sulfona & & & & \\
\hline
\end{tabular}

${ }^{\mathrm{a} C o e f i c i e n t e ~ d e ~ v a r i a c ̧ a ̃ o ~}(\mathrm{n}=3)$

Análise quantitativa por HPLC/fluorescência

Um cromatograma HPLC/FS mostrando a separação de alguns $\mathrm{N}$-metil-carbamatos (NMCs) e seus produtos de degradação é mostrado na Figura 5. Em relação aos cromatogramas obtidos pelo sistema HPLC/MS, que emprega bombas binárias (fase móvel acetonitrila/ água), a resolução para HPLC/FS foi melhor; o uso do metanol como um terceiro modificador orgânico foi eficiente para separar os picos do propoxur e do carbofuran. Pelos dados constantes na Tabela 4, pode-se verificar que a detecção por APCI/MS mostrou-se menos sensível que por FS. Entretanto, ambas as técnicas apresentam elevada sensibilidade, o que as torna adequadas às análises de resíduos desses compostos em níveis de partes por bilhão, considerando que os extratos podem ser previamente concentrados mediante suave corrente de $\mathrm{N}_{2}$. Os limites de detecção variaram entre 0,2 e $0,5 \mathrm{ng}$ para HPLC/ FS, tendo sido menores que aqueles encontrados por Pleasance et al. ${ }^{17}$ e comparáveis àqueles obtidos por outros laboratórios ${ }^{18,19}$.

\section{Eficiência do método SFE para extração dos carbamatos}

Como visto na parte experimental, os inseticidas carbamatos foram extraídos da matriz vegetal por meio do sistema SFE mostrado na Figura 1, com $\mathrm{CO}_{2}$ a diferentes valores de temperatura e pressão. Os dados constantes na Tabela 5 indicam que os compostos foram eficientemente extraídos através dos métodos A, E e F (os parâmetros operacionais encontram-se na Tabela 2). Pode-se verificar que menores recuperações foram obtidas quando o procedimento SFE foi realizado em temperaturas mais altas, e utilizando-se o metanol como modificador. A adição da acetonitrila como agente modificador serviu para melhorar a partição do gás carbônico na amostra vegetal, favorecendo a interação do fluido supercrítico com os componentes da matriz e, conseqüentemente, a extração dos analitos.

Curiosamente, em todos os métodos testados, foi impossível a detecção do carbaril. A Figura 3 mostra apenas uma amostra fortificada; nas amostras reais, o pico do carbaril foi considerado desprezível. Isto vem mais uma vez confirmar a rápida degradação deste pesticida, em valores de temperatura acima de $35^{\circ} \mathrm{C}^{20,21}$, com conseqüente formação do seu principal produto de degradação, o 
1-naftol, que é cerca de 3 vezes mais tóxico que o composto precursor $^{13}$. Neste trabalho, a presença de elevados teores do 1-naftol foi verificada em todos os extratos SFE analisados (Figura 4); temperaturas elevadas favoreceram, ainda, a formação dos produtos de de-
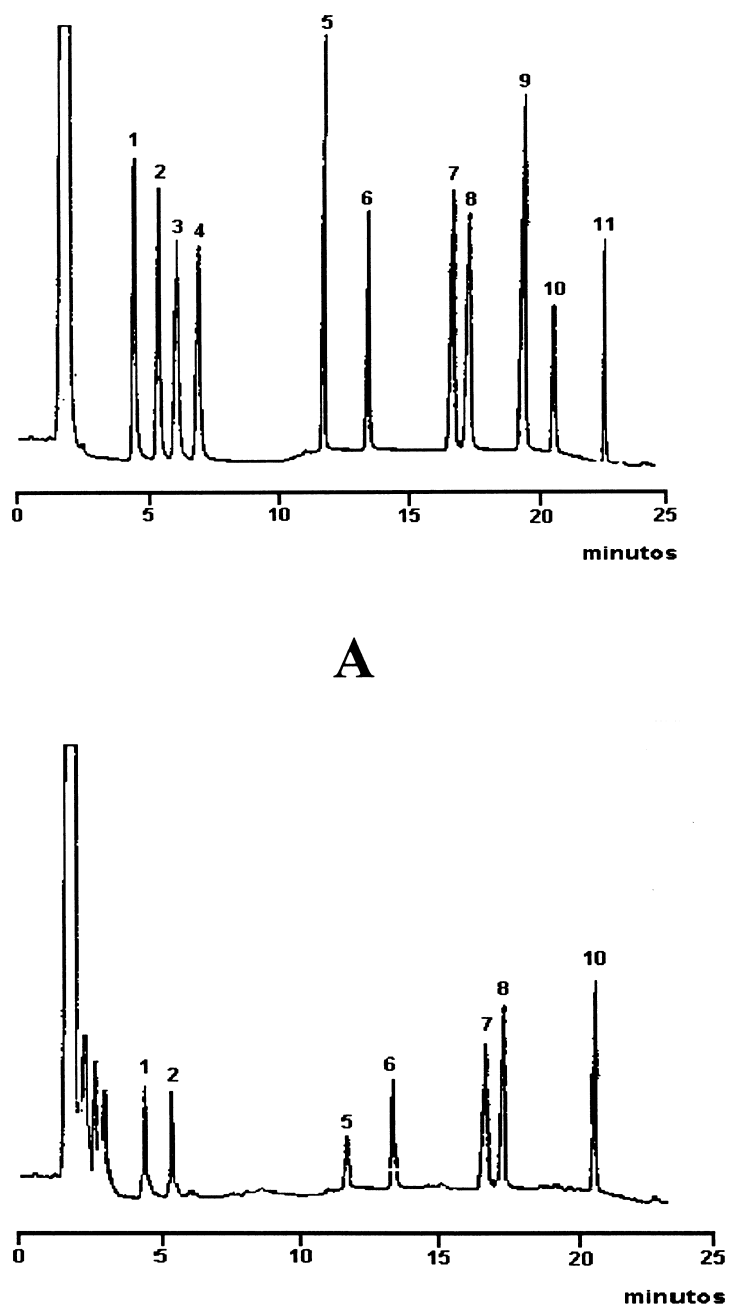

B

Figura 5. A - Cromatograma de uma mistura de padrões de carbamatos e alguns dos seus produtos de degradação (concentração: 1 mg. $L^{-1}$ ), analisada por HPLC/FS, conforme condições descritas na parte experimental. (1) Aldicarb sulfóxido; (2) Aldicarb sulfona; (3) Oxamil; (4) Metomil; (5) 3hidroxicarbofuran; (6) Aldicarb; (7) Propoxur; (8) Carbofuran; (9) Carbaril; (10) 1-naftol; (11) Metiocarb. B - Cromatograma de um dos extratos obtidos após procedimento de SPE (método E) gradação do aldicarb, nas formas oxidadas sulfona e sulfóxido (Figuras 4 e 5), o que foi comprovado pelos baixos índices de recuperação deste composto para a maioria dos métodos testados, exceto para o método F. Como os fatores relação Hydromatrix ${ }^{\circledR} /$ amostra e pressão do fluido foram mantidos constantes em todos os procedimentos SFE testados, acredita-se que o parâmetro que mais influenciou nos resultados de recuperação foi o modificador. Pode-se observar que melhores resultados foram obtidos com menores quantidades de acetonitrila (3\%), porém o tempo de extração foi maior (35 min), num fluxo de fluido supercrítico moderado $\left(1,5 \mathrm{~mL} \cdot \mathrm{min}^{-1}\right)$.

Com exceção do método $\mathrm{D}$, que utiliza $5 \%$ de metanol como modificador, e menor tempo de extração (20 min), os demais métodos SFE foram satisfatórios para a extração do inseticida carbofuran na amostra analisada. Deste modo, caso seja de interesse analisar somente este composto, torna-se conveniente eleger um procedimento que ofereça maiores vantagens econômicas, com o é o caso do método C (ver Tabela 2).

O método D apresentou, ainda, a desvantagem de possuir menor precisão, indicada pelos maiores valores de coeficiente de variação. Convém mencionar que, no presente trabalho, tomou-se o cuidado de realizar, entre cada processo SFE efetuado, uma criteriosa limpeza das células de extração e dos frits (tampas das células que contém a membrana por onde atravessa o fluido supercrítico). Esta limpeza consistiu de uma lavagem com solução de Extran alcalino a $20 \%$, por $10 \mathrm{~min}$ em banho de ultrassom, seguida de enxágüe seqüencial com água quente, água fria e água deionizada, antes da secagem em estufa a $75^{\circ} \mathrm{C}$. Os frits foram, ainda, sonicados com acetona por 10 min e depois enxaguados com água deionizada, antes da secagem. Esta cuidadosa limpeza foi realizada com o objetivo de evitar a contaminação das células, o que poderia resultar em valores superestimados nas extrações subseqüentes. Portanto, o fato de os coeficientes de variação terem sido relativamente elevados, chegando a atingir a faixa de 9 a $28 \%$ para alguns compostos, não pode ser creditado à ineficiente limpeza do material. A baixa reprodutibilidade, para tais casos, sugere que procedimentos SFE devem ser testados em outros tipos de amostras vegetais, a fim de verificar-se se há algum efeito de matriz. Contudo, deficiências em relação às reprodutibilidades das técnicas SFE, quando aplicadas às análises de pesticidas em amostras vegetais, foram também comentadas por Lopez-Avila et al. ${ }^{8}$. Este é um dos principais motivos pelos quais torna-se difícil a inclusão de métodos de preparo de amostras baseados nos procedimentos SFE, como alternativas às metodologias convencionais de bancada, o que pode ser comprovado pela não-aceitabilidade de tais procedimentos por parte dos órgãos que estabelecem e divulgam métodos oficiais de análise (por exemplo, o AOAC).

\section{CONCLUSÕES}

Neste trabalho, foi avaliada a eficiência de diferentes procedimentos de extração em fluido supercrítico (SFE) para análise de in-

Tabela 5. Valores de recuperação, após extração em fluido supercrítico, dos carbamatos estudados

\begin{tabular}{|c|c|c|c|c|c|c|}
\hline \multirow[t]{2}{*}{ Composto } & \multicolumn{6}{|c|}{ Método/Recuperação (\%)* } \\
\hline & A & B & $\mathrm{C}$ & $\mathrm{D}$ & $\mathrm{E}$ & $\mathrm{F}$ \\
\hline Aldicarb & $12(11,3)$ & $17(15,5)$ & $16(3,1)$ & $23(23,4)$ & $55(2,8)$ & $92(1,8)$ \\
\hline Carbaril & - & - & - & - & - & - \\
\hline Carbofuran & $80(9,3)$ & $118(3,7)$ & $96(2,5)$ & $28(6,1)$ & $87(3,7)$ & $86(3,2)$ \\
\hline Metomil & $81(3,7)$ & $111(4,8)$ & $33(21,5)$ & $18(28,4)$ & $96(2,6)$ & $95(1,8)$ \\
\hline Propoxur & $77(3,3)$ & $150(2,3)$ & $40(15,5)$ & $25(12,1)$ & $89(4,6)$ & $72(4,1)$ \\
\hline
\end{tabular}

*Os dados entre parênteses referem-se aos coeficientes de variação, expressos em \% (n=3). 
seticidas carbamatos em amostras de batata. Para as determinações cromatográficas, duas técnicas foram utilizadas: HPLC/fluorescência (quantificação) e HPLC-APCI/MS (quantificação/confirmação de produtos de degradação). A especificidade e a seletividade que podem ser alcançadas em análises diretas de carbamatos em matrizes complexas, por HPLC/FS, por si só justificam o seu uso para quantificação dos compostos. No presente estudo, a confirmação por HPLC/MS utilizando a interface APCI foi necessária, uma vez que outras metodologias estavam sendo avaliadas (os procedimentos SFE). No entanto, é conveniente mencionar que a técnica por HPLC/ MS é extremamente cara, não só pelo fato de que a própria análise requer grandes volumes de solventes, mas também devido à necessária manutenção do equipamento. A vantagem adicional, que se constitui no grande trunfo da técnica analítica HPLC-APCI/MS, é que se pode, a um só tempo, determinar os resíduos dos pesticidas e confirmar a presença desses resíduos e de outros que porventura apareçam no cromatograma. A técnica SFE mostrou-se eficiente, na maioria dos casos, exceto para o pesticida carbaril, que não pôde ser extraído das amostras, devido provavelmente a algum efeito de matriz. Comparados às técnicas tradicionais de extração, envolvendo uso de solventes orgânicos, os procedimentos SFE mostraram-se extremamente rápidos, baratos e ambientalmente mais limpos. Entretanto, para alguns compostos, a reprodutibilidade foi insatisfatória, evidenciando a necessidade de estudos mais aprofundados.

\section{AGRADECIMENTOS}

Os autores agradecem o auxílio financeiro do CNPq, através do seu Programa de Bolsas no Exterior, que possibilitou a execução deste trabalho no Conselho Superior de Investigações Científicas, em Barcelona, Espanha.

\section{REFERÊNCIAS}

1. Markus, C. M.; Food and Drug Journal 1992, 47, 701.

2. Ambrus, A.; Thier, H. P.; Pure Appl. Chem. 1986, 58, 1035.

3. Stuart, I. A.; MacLachlan J.; McNaughtan, A.; Analyst 1996, 121, 11

4. Berger, T. A.; Wilson, W. H.; Deye, J. F.; J. Chromatogr. Sci. 1994, 32, 179.

5. Yang, S. S.; Goldsmith, A. I.; Smetena, I.; J. Chromatogr., A 1996, 754, 3.

6. Bernal, J. L.; Delnozal, M. J.; Jimenez, J. J.; Chromatographia 1992, 34, 468.

7. Hitchen, S. M.; Dean, J. R. Em Applications of Supercritical Fluids in Industrial Analysis; Dean, J. R., ed.; Blackie: Glasgow, 1993, cap. 1.

8. Lopez-Avila, V.; Charan, C.; Van Emon, J. Em Immunoassay for Residue Analysis; ACS Symposium Series, Beier, R. C.; Stanker, L. H., ed.; California, 1995, cap. 5.

9. Valverde-Gracía, A.; Fernandez-Alba, A.; Agüera, A.; Contreras, M.; J. Assoc. Off. Anal. Chem. Int. 1995, 78, 867.

10. Valverde-Gracía, A.; Fernandez-Alba, A.; Contreras, M.; Agüera, A.; J. Agric. Food Chem. 1996, 44, 1780.

11. Hopper, M. L.; J. Assoc. Off. Anal. Chem. Int. 1997, 80, 639.

12. Nunes, G. S.; Alonso, R. M.; Ribeiro, M. L.; Barceló, D.; J. Chromatogr. A 2000, 888, 113 .

13. Nunes, G. S.; Marco, M-P.; Barceló, D.; Ribeiro, M. L.; J. Chromatogr., A 1998, 823, 109

14. Niessen, W. M. A.; Van der Greef, J.; Liquid Chromatography-Mass Spectrometry: Principles and Applications, Marcel Dekker, Inc.: New York, 1992, p. 229-245.

15. Volmer, D.; Levsen, K.; Honing, M.; Barceló, D.; Abián, J.; Van Baar Gelpí, B. L. M.; Th. Brinkman, U. A.; J. Am. Soc. Mass Spectrom. 1995, 6, 656.

16. Doerge, D. R.; Bajic, S.; Rapid Commun. Mass Spectrom. 1992, 6, 663.

17. Pleasance, S.; Anacleto, J. F.; Bailey, M. R.; North, D. H.; J. Am. Soc. Mass Spectrom. 1992, 3, 378.

18. Slobodnik, M.; Jager, M.E.; HoeskstraOussoren, S.J.F ; Honing, M.; VanBaar, B.L.M.; Brinkman, U.A.T.; J. Mass Spectrom. 1997, 32, 43.

19. Cairnes, T.; Siegmund, E. G.; Doose, G. M.; Langham, W.S.; Bull. Environ. Contam. Toxicol. 1984, 32, 310.

20. Nunes, G. S.; Ribeiro, M. L.; Polese, L.; Barceló, D.; J. Chromatogr., A 1998, 795, 43

21. Toscano, I.; Ribeiro, M. L., Rocha, J. C.; Nunes, G. S.; Barceló, D.; Quim. Nova 2000, 23, 466 